\title{
Finite Element Simulation Analysis of Qiaoli Reinforced Concrete U-shaped Aqueduct
}

\author{
Dongyu $\mathrm{Ji}^{\mathrm{a}}$ \\ Hunan Urban Construction College, Xiangtan, Hunan Province 411101, P.R. China \\ ahnjdy@126.com
}

Keywords: U-shaped aqueduct, Finite element method, Simulation analysis, Stress distribution

\begin{abstract}
This paper adopts general finite element software to carry out three-dimensional finite element simulation analysis for Qiaoli reinforced concrete U-shaped aqueduct. Considering five combination cases in aqueduct's construction and operating process, researching variation laws of the aqueduct's stress and displacement. Analysis results show that design scheme of Qiaoli reinforced concrete U-shaped aqueduct is reasonable, it can meet design requirements. Analysis results provide some theory references for design of reinforced concrete U-shaped aqueduct.
\end{abstract}

\section{Introduction}

Qiaoli aqueduct is located main canal of Tongrenqiao reservoir, which is located Changsha county in Hunan province. Design flow rate is $2.4 \mathrm{~m}^{3} / \mathrm{s}$, longitudinal slope is $1 / 1500$, overall length is $108 \mathrm{~m}$. Aqueduct structure is simply beam-supported aqueduct, aqueduct is reinforced concrete structure, section of aqueduct is U-shaped. The span of aqueduct is $24 \mathrm{~m}$, it shelves on the frame, height of frame is $10 \mathrm{~m}$, frame shelves on reinforced concrete hollow thin-walled pier. The foundation of pier built on uniform weathered rock ${ }^{[1]}$. Aqueduct semicircle section's inside radius $\mathrm{R}=0.9 \mathrm{~m}$, clear height is $1.6 \mathrm{~m}$, side wall thickness is $0.1 \mathrm{~m}$, thickness of aqueduct's bottom is $0.2 \mathrm{~m}$. There layouts a pull rod every $2 \mathrm{~m}$ on the upper edge of aqueduct, pull rod's section size is $0.15 \mathrm{~m} \times 0.15 \mathrm{~m}$. Aqueduct's design level is $1.35 \mathrm{~m}$, maximum level is $1.45 \mathrm{~m}$.

\section{Calculation Model}

Model Parameters. Concrete strength grade of Qiaoli aqueduct is C30, elastic modulus $\mathrm{E}_{1}=30 \mathrm{GPa}$, Poisson ratio $\mu_{1}=0.167^{[2]}$, density $\gamma_{1}=24 \mathrm{kN} / \mathrm{m}^{3}$. Concrete strength grade of the bent is C20, elastic modulus $\mathrm{E}_{2}=25.5 \mathrm{GPa}$, Poisson ratio $\mu_{2}=0.167$, density $\gamma_{2}=24 \mathrm{kN} / \mathrm{m}^{3}$. Concrete strength grade of the pier is C15, elastic modulus $E_{3}=22 \mathrm{GPa}$, Poisson ratio $\mu_{3}=0.167$, density $\gamma_{3}=24 \mathrm{kN} / \mathrm{m}^{3}$.

Model Element. The aqueduct structure model is divided by eight nodes isoparametric block element. The element is often applied to three-dimensional model of entity structure, it has plasticity, creep, expansion, stress rigidization, large deformation and large strain characteristics. The element has eight nodes, each node has three translational degree of freedoms ${ }^{[3]}$. Aqueduct structure finite element calculation model is shown in Fig.1.

Calculation Cases. Considering mechanical characteristics of the aqueduct structure in construction and operating process ${ }^{[4]}$, researching five calculation cases as follows. Case 1 , aqueduct weight and wind load; case 2, aqueduct weight, half of aqueduct level $(0.9 \mathrm{~m})$ and wind load; case 3, aqueduct weight, design level $(1.35 \mathrm{~m})$ and wind load; case 4 , aqueduct weight, maximum level $(1.45 \mathrm{~m})$ and wind load; case 5 , aqueduct weight, design level $(1.35 \mathrm{~m})$, wind load and earthquake effect.

\section{Aqueduct Structure Analysis}

Analysis Paths. When finite element analysis for Qiaoli reinforced concrete U-shaped aqueduct is proceeded, in calculation model's one half of span's section, one quarter of span's section, one eighth of span's section, from aqueduct's top to bottom, eight calculation points are selected 
respectively along clockwise in the aqueduct's internal surfaces. Three analysis paths are confirmed, path 1, aqueduct's one half of span's section; path 2, aqueduct's one quarter of span's section; path 3 , aqueduct's one eighth of span's section. Stress and deformation distribution of these analysis paths are provided in the paper.

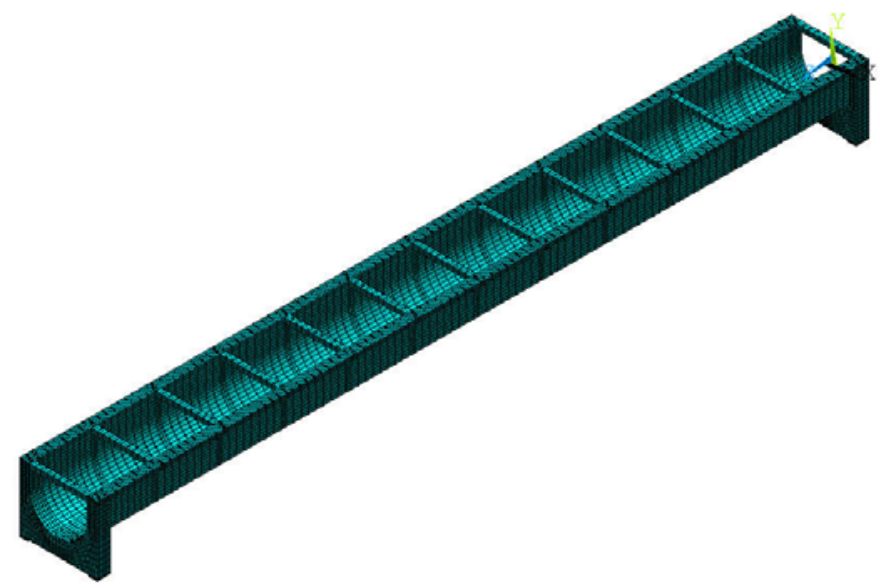

Fig.1 Aqueduct structure finite element calculation model

Stress Analysis. After three-dimensional finite element simulation analysis of reinforced concrete U-shaped aqueduct is proceeded, obtaining aqueduct's calculation point's longitudinal stress values under various cases in construction and operating process, the longitudinal stress values are listed in the table 1.

Table 1. Calculation point's longitudinal stress values on the aqueduct's analysis path under various cases( $\mathrm{MPa})$

\begin{tabular}{lccccccccc}
\hline Calculation Point & 1) & (2) & (3) & (4) & (5) & 6) & (7) & (8) \\
\hline \multirow{4}{*}{ Case 1 } & Path 1 & -2.17 & -2.35 & -1.29 & -0.26 & 0.81 & 1.70 & 2.23 & 2.38 \\
& Path 2 & -1.50 & -1.65 & -0.97 & -0.31 & 0.43 & 1.08 & 1.50 & 1.65 \\
& Path 3 & -0.99 & -0.76 & -0.55 & -0.32 & -0.01 & 0.33 & 0.59 & 0.74 \\
Case 2 & Path 1 & -3.82 & -4.12 & -2.23 & -0.42 & 1.47 & 3.03 & 3.98 & 4.22 \\
& Path 2 & -2.64 & -2.87 & -1.62 & -0.41 & 0.89 & 2.00 & 2.71 & 2.93 \\
& Path 3 & -1.87 & -1.35 & -0.85 & -0.36 & 0.21 & 0.75 & 1.13 & 1.31 \\
Case 3 & Path 1 & -4.80 & -5.25 & -2.88 & -0.54 & 1.88 & 3.91 & 5.11 & 5.43 \\
& Path 2 & -3.31 & -3.66 & -2.08 & -0.50 & 1.18 & 2.61 & 3.50 & 3.77 \\
& Path 3 & -2.48 & -1.77 & -1.10 & -0.41 & 0.34 & 1.05 & 1.49 & 1.69 \\
Case 4 & Path 1 & -5.01 & -5.50 & -3.02 & -0.57 & 1.98 & 4.10 & 5.36 & 5.69 \\
& Path 2 & -3.44 & -3.84 & -2.19 & -0.53 & 1.24 & 2.75 & 3.68 & 3.96 \\
& Path 3 & -2.63 & -1.88 & -1.16 & -0.42 & 0.37 & 1.12 & 1.58 & 1.78 \\
Case 5 & Path 1 & -5.11 & -5.65 & -3.21 & -0.80 & 1.71 & 3.80 & 5.06 & 5.43 \\
& Path 2 & -3.44 & -4.02 & -2.68 & -1.27 & 0.43 & 2.05 & 3.23 & 3.77 \\
& Path 3 & -1.74 & -1.78 & -1.83 & -1.69 & -1.05 & -0.05 & 0.94 & 1.69 \\
\hline
\end{tabular}

We can see from table 1, under various cases, the upper half of aqueduct's section is compressed, the lower part of aqueduct's section is tensile, neutral axis is located between calculation point (4) and (5). Aqueduct's maximum longitudinal tensile stress value is 2.38MPa under case 1 , it is located bottom of path 1. Maximum longitudinal tensile and compressive stress value in the aqueduct increased gradually along with the increase of water level. Under same case, tensile and compressive stress values of path 1 are larger, tensile and compressive stress values of path 2 are small, tensile and compressive stress values of path 2 are smaller. This is mainly because beam-supported aqueduct's force characteristics is similar with beam structure under aqueduct 
weight and water pressure, bending moment of midspan is maximum, bending moment of ends is minimum, so such stress distribution law is produced. Stress values case 3 and case 5 differ not quite at aqueduct's bottom, but stress values difference are bigger at aqueduct's side wall, this is mainly because transverse earthquake effect produces stress distribution law.

Because case 5 is serious condition of aqueduct in operating process. We obtain aqueduct's typical section's contour maps of first principal stress under case 5, contour maps are shown from Fig.2 to Fig.5.

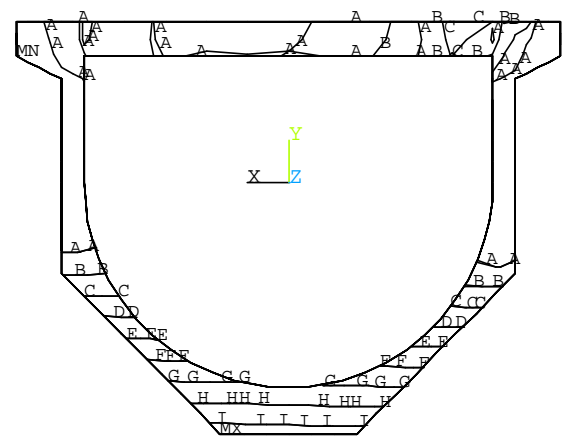

Fig.2 Contour map of one half of span section's first principal stress $(\mathrm{Pa})$

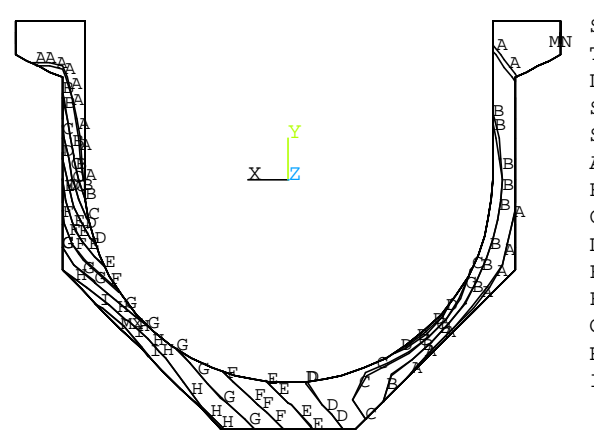

Fig.4 Contour map of one eighth of span section's first principal stress $(\mathrm{Pa})$
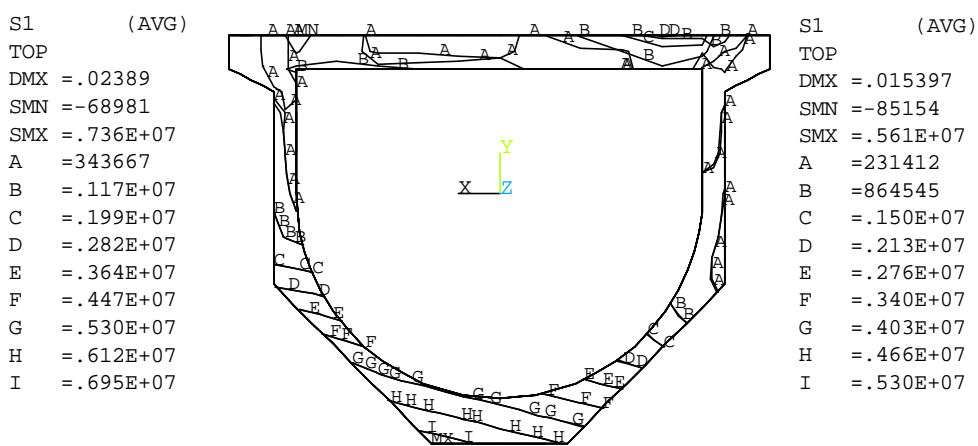

Fig.3 Contour map of one quarter of span section's first principal stress $(\mathrm{Pa})$

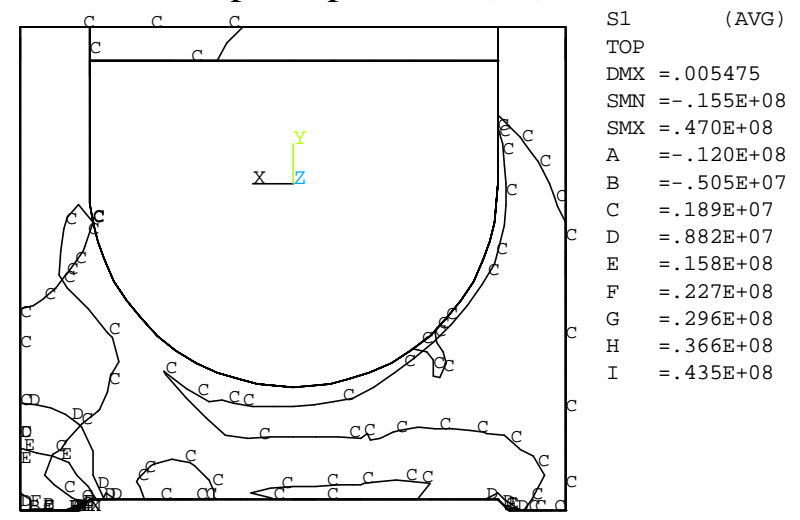

Fig.5 Contour map of ends section's first principal stress $(\mathrm{Pa})$

We can see from Fig.2 to Fig.5, aqueduct's first principal stress value is maximum in the midspan section, maximum first principal stress value is $6.95 \mathrm{MPa}$, and stress distribution is regular, the tensile stress mainly distributed in lower part of aqueduct's section, tensile stress is layered distribution. Aqueduct's first principal stress value is larger in the one quarter of span section, maximum first principal stress value is $5.30 \mathrm{MPa}$, stress value increase gradually from aqueduct's top to bottom, tensile stress is basically layered distribution. Aqueduct's first principal stress value is smaller in the one eighth of span section, maximum first principal stress value is 3.92MPa, stress distribution is more complicated, stress of aqueduct's section is tensile stress. First principal stress distribution of aqueduct's ends is extremely complicated, support appears serious stress concentration phenomenon, maximum first principal stress value is $43.5 \mathrm{MPa}$.

Deformation Analysis. Through deformation analysis of Qiaoli reinforced concrete U-shaped aqueduct, getting aqueduct's vertical displacement variation law under various cases, cloud maps of aqueduct's vertical displacement are shown from Fig.6 to Fig.9.

We can see from Fig. 6 to Fig.9, aqueduct's vertical displacement distribution law is similar under various cases, because of the earthquake effect, displacement distribution slight changes under case 5 , but it has a little influence. aqueduct's maximum vertical displacement is $7.89 \mathrm{~mm}$ under case 1 , aqueduct's maximum vertical displacement is $17.86 \mathrm{~mm}$ under case 3 , aqueduct's maximum vertical displacement is $18.73 \mathrm{~mm}$ under case 4 , aqueduct's maximum vertical displacement is $18.17 \mathrm{~mm}$ under case 5, maximum vertical displacement appears midspan section. It follows that water pressure has great influence on aqueduct's vertical displacement. 


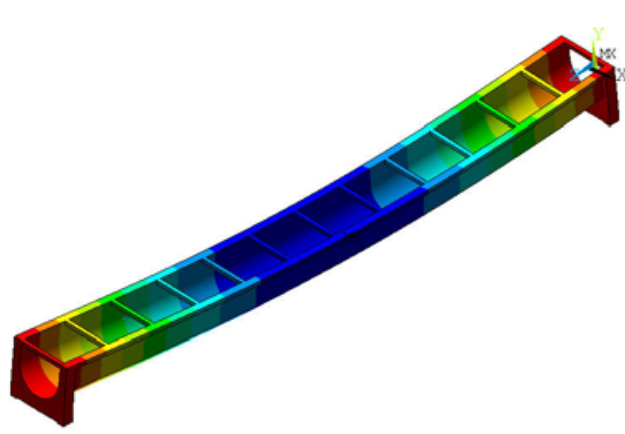

Fig.6 Cloud map of aqueduct's vertical displacement under case $1(\mathrm{~m})$

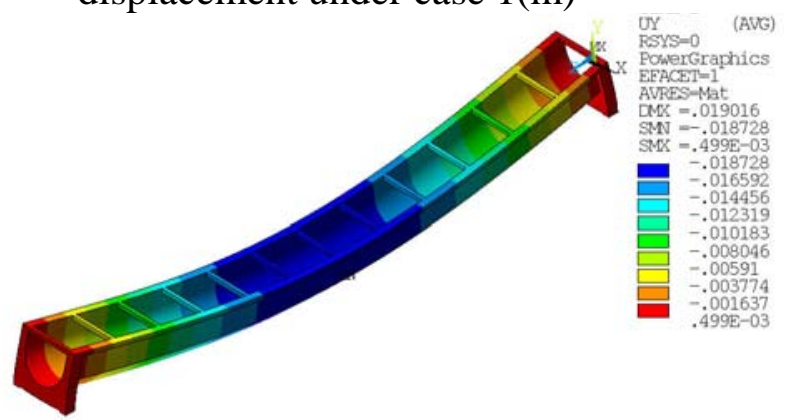

Fig.8 Cloud map of aqueduct's vertical displacement under case 4(m)

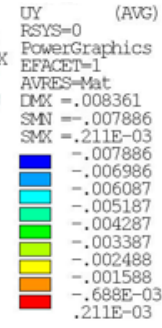

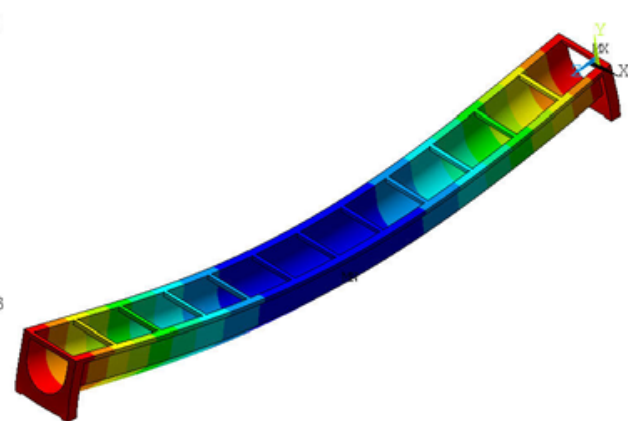

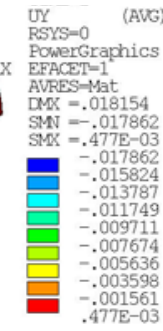

Fig.7 Cloud map of aqueduct's vertical displacement under case 3(m)

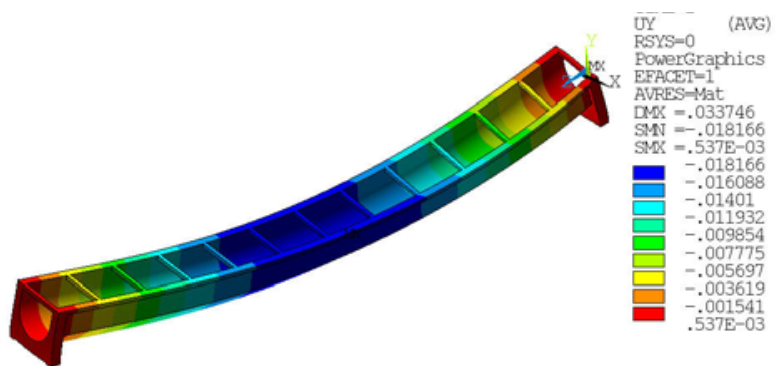

Fig.9 Cloud map of aqueduct's vertical displacement under case 5(m)

\section{Conclusion}

From the above, design scheme of Qiaoli reinforced concrete U-shaped aqueduct is economic and reasonable, force of aqueduct structure is explicit, through reinforcement to strengthen, stress values can meet strength requirements. Aqueduct's vertical displacement values are smaller, displacement values can meet rigidity requirements.

\section{References}

[1] W. Zhao: Rock Mechanics(Central South University Press, China 2010)(in Chinese)

[2] SL/T191-96: Design Code for Hydraulic Concrete Structures(China Water Conservancy and Hydropower Press, China 1996)(in Chinese)

[3] G.R. Chen: Finite Element Method Principles and Applications(Science Press, China 2009)(in Chinese)

[4] H.ZH. Zhu, D.L. Chen, F.N. Guan: Aqueduct(China Water Conservancy and Hydropower Press, China 2005)(in Chinese) 